\title{
Situações Familiares na Obesidade Exógena Infantil do Filho Único
}

\section{Family Situations in the Childhood Obesity of the Only Child}

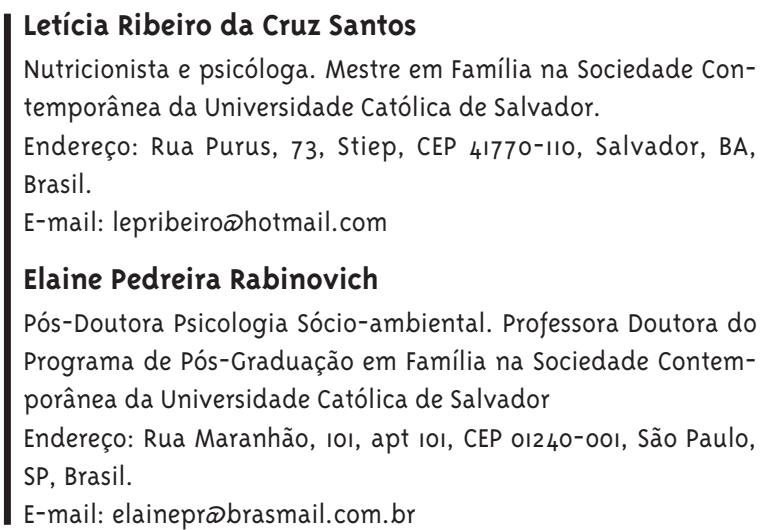

E-mail: elaineprøbrasmail.com.br

\section{Resumo}

Este é um trabalho qualitativo cujo objetivo foi aprofundar a compreensão da dinâmica familiar de filhos únicos obesos na infância. Crianças de oito famílias participaram do estudo: quatro meninos e quatro meninas, entre 7 e 10 anos, de grupo socioeducacional alto e baixo com avaliação nutricional para obesidade: IMC acima do percentil 97. Foram aplicados no domicílio os seguintes instrumentos: entrevista semiestruturada, teste projetivo Scenotest e avaliação nutricional. A análise apoiou-se na teoria das configurações vinculares (Berenstein e Puget). Os resultados apontaram dinâmicas familiares envolvendo contextos de natureza social, cultural e histórica da sociedade que parecem favorecer ambas as condições: a da obesidade infantil e a de filho unigênito. Elementos sociais enfatizando o individualismo se refletem em nível familiar e íntimo. Assim, a criança pode vir a encontrar, logo ao nascer, condições propiciadoras para que a vinculação básica com a figura materna não se processe de modo pleno, ocasionando deslocamento de parte do que não recebe para a satisfação no alimento. Além disso, a cultura do consumo interfere no modo e tipo de alimentação oferecida, na ludicidade e da sociabilidade infantil, assim como o estreitamento das possibilidades vinculares: intrapessoais, interpessoais, transpessoais, acrescentando-se o fato de não ter irmãos. Esse estudo mostrou que, embora nem todo filho único seja obeso e nem todo obeso seja filho único, uma condição pode ser facilitadora da outra na medida em que a situação socioculturalhistórica da sociedade de consumo hipermoderna parece direcionar a família a ambas as condições. Palavras-chave: Obesidade infantil; Filho único; Relações Familiares. 


\section{Abstract}

This study aims to deepen the understanding of the family dynamics of obese only children using a qualitative methodology. Its sample included eight families: four girls and four boys between 7 and 10 years old from high and low social-educational groups, with a nutritional evaluation for obesity: body mass index $(\mathrm{BMI})>97^{\text {th }}$ percentile. The following instruments were applied at their homes: a semi-structured interview, the projective Scenotest and a nutritional evaluation. The analysis was based on the theory of bond configurations (Berenstein and Puget). Its results showed that family dynamics involving contexts of social, cultural and historical nature of the society seem to favor both conditions: child obesity and only child. Social elements emphasizing individualism reflect on the familial and intimate level. The child can face, as soon as he/she is born, conditions for an unsatisfactory basic bond with the mother. The lack of a bond drives the child's satisfaction to food. Besides, the consumer culture interferes with the kind of food that is offered and with the way it is offered, and with the child's social skills; furthermore, it interferes with the decrease in the creation of possible bonds: intrapersonal, interpersonal and transpersonal, in addition to the fact that the child does not have siblings. This study showed that, although not every only child is obese and although not every obese child is an only child, one condition can be a facilitator of the other, as the social, cultural and historical situation of the hypermodern consumer society seems to lead the family to both conditions.

Keywords: Childhood Obesity; Only Child; Family Relationships.

\section{Introdução}

A obesidade na sociedade moderna e globalizada tem se espalhado a níveis alarmantes em todas as faixas etárias e em todas as populações. Devido à magnitude dessa epidemia, deve-se dar ênfase especial às medidas preventivas infantis, já que o tratamento em crianças constitui-se em um melhor prognóstico do que em adultos (Fisberg, 2005).

É uma doença crônica, rica em complexidade, com etiologia multifatorial com variáveis biológicas, psicológicas, sociais e econômicas, que envolve também aspectos ambientais e genéticos. Pode ser explicada nos hiperfágicos por alterações culturais, emocionais, regulatórias e metabólicas (Fisberg, 2005). É de difícil tratamento, de alta morbidade e mortalidade, cujo risco aumenta progressivamente de acordo com o ganho de peso (Herscovici, 1997) resultante do desequilíbrio crônico entre a ingestão e o gasto energético. Ocasiona consequências biológicas e psicossociais, identificadas em todas as faixas etárias (Bernardi e col., 2005).

A obesidade infantil tem aumentado consideravelmente em nível mundial, sendo considerada uma epidemia em algumas áreas e em ascendência em outras. O International Obesity Task Force preconizou no o 2000 um total mundial de crianças obesas em torno de 45 milhões de crianças (IOTF 2009).

No Brasil e na região nordeste, o modelo da prevalência mundial está se reproduzindo. Em estudo realizado por Leão e colaboradores (2003) com escolares em Salvador (BA), em idade entre 5 e 10 anos, verificou-se que as crianças pertencentes à escola particular apresentaram 30\% de prevalência de obesidade, enquanto as de escola pública, $8 \%$.

A marca do individualismo é um dos elementos que ocorrem em paralelo à diminuição do tamanho das famílias. Nesse sentido, nas famílias contemporâneas, em que as crianças ocupam a centralidade, a ênfase na individualização manifesta-se nos arranjos dos hábitos e nos fazeres da família como, por exemplo, a criança dispor de espaços próprios desde o seu nascimento dentro de um paradigma de que necessita deles para o seu desenvolvimento. (Singly, 2000).

Nos últimos dez anos, no Brasil, houve um aumento de famílias com apenas um filho. Segundo 
dados da Pesquisa Nacional por Amostra de Domicílio (PNAD), do IBGE (2007), o número de mulheres com apenas um filho subiu de $25,8 \%$ para $30,7 \%$. Assim, o número de filhos tem diminuído, sobretudo nas classes média e média-alta, construindo-se um paralelo entre as mudanças dos dinamismos familiares decorrentes da inserção da mulher no mercado de trabalho, conduzida por reivindicações de maior liberdade, realização pessoal e por necessidades de orçamento familiar (Petrini, 2007).

No que se refere à obesidade segundo as classes sociais, nos países desenvolvidos existe uma relação negativa entre o alto nível socioeconômico e a obesidade. No que diz respeito aos países em desenvolvimento, encontra-se uma relação positiva entre alto nível socioeconômico e obesidade (Fisberg, 2005).

A dinâmica familiar da criança filha única obesa pode configurar uma complexidade da teia biopsicossocial familiar. Para Kehl (2003), quando os pais estão ausentes por motivos variados como divórcio, trabalho, viagens, pode emergir uma dificuldade do uso de autoridade na família. Para reparar sua falta em casa, muitas mães ou cuidadores permitem que os filhos comam sem moderação. Na atualidade, os sistemas familiares encontram-se em situações de emaranhamento, configurados por conflitos nas relações entre mãe, filho(a) e pai que vivenciam o prolongamento da simbiose do desenvolvimento vincular mãe e filho(a) na primeira infância. 0 pai, por sua vez, pode apresentar distanciamento na relação com o filho e encontrar-se fragilizado como figura de autoridade. A tentativa de aproximação pode se traduzir em uma permissividade alimentar e em dificuldade em colocar limite em seu filho. (SBP, 2008).

Na Psicanálise das Configurações Vinculares, os psicanalistas argentinos Berenstein (2007) e Puget (2003) preconizam que a família surge de uma estrutura familiar inconsciente, de um conjunto de lugares e de vínculos e da maneira particular em que eles são investidos. Nasce também de modelos e ofertas identificatórias individuais, familiares e culturais, tanto de vínculos atuais quanto transgeracionais.

Berenstein (2007) estabelece a distinção entre "problemas familiares" e "situações familiares" para enfatizar que, uma situação ao ser constituída como problema, já implicaria em uma normatização, ou seja, em um padrão de cujo afastamento constituir-se-ia em um "problema”. Pode-se definir, então, "situação da obesidade infantil do filho único" como um espaço familiar sócio-histórico em que a obesidade resulta de uma interação dinâmica entre vários níveis em que a criança, sua família, seu grupo socioeducacional e seu momento histórico estão inseridos.

Berenstein (2001) articula um modelo de aparelho psíquico no qual se organizam zonas diferenciáveis, chamadas por ele de espaços psíquicos. Situa o espaço intrasubjetivo, o intersubjetivo e o transubjetivo, que inscrevem marcas e representações que elaboram diferentes dinâmicas e que têm origem no início da vida. A ideia central é a de que esses espaços psíquicos têm, cada um, a sua abrangência, constituindo o sujeito desde a sua origem mais remota até a sua plena inserção na cultura.

O espaço intrasubjetivo é o que corresponde ao intrapsíquico na teoria clássica e abrange as fantasias, desejos e as relações de objeto. No espaço intersubjetivo, estão o sujeito e os outros. O espaço transubjetivo é o sociocultural, o macro contexto em que cada sujeito estabelece relações com os valores, ideologias, crenças e a própria história. São espaços em que são constituídas as relações com a sociedade a qual o indivíduo pertence, a partir da experiência estabelecida com a participação das figuras parentais, exercendo a mãe o papel de porta-voz da cultura (Berenstein, 2007).

\section{Obesidade infantil e teoria vincular}

Cada época histórica gera um tipo de subjetividade e de vínculo familiar. Em nossa época, a linguagem do sucesso e da eficácia é significativa. Tanto o sujeito quanto a família estão impregnados da necessidade de obter sucesso. Eficácia e aparência (a imagem de si) são propostas do imaginário social como modos de uma subjetividade, individual e familiar, produzida no capitalismo.

A criança não apenas está vinculada à sua realidade familiar, mas surge imersa em um "conjunto contextualizado”, aí incluídos o político e o econômico. 0 espaço dessa construção é o grupo familiar em que interagem diversas formas de vínculo (Puget, 2003). Nesse espaço, que simultaneamente antecede 
à existência da criança, e é alterada por ela, a realidade intersubjetiva é experimentada de maneira primária pela criança, objetivando a experiência de vivenciar o lugar de trocas vinculares, investimentos narcísicos, de separação e individuação (Magalhães e Féres-Carneiro, 2004).

Assim, o desenvolvimento desse tema tem como pressuposto que o sintoma da obesidade infantil se apresenta como consequência de vários espaços, intrasubjetivo, intersubjetivo e transubjetivo, associados a transformações socioeconômicas e ideológicas na configuração da família.

Desse modo, este estudo tem como objetivo geral aprofundar a compreensão das relações familiares de filhos únicos portadores de obesidade exógena na infância. Tem como objetivos específicos: identificar o papel da família e de seus membros na etiologia e atitude adiante da obesidade infantil do filho único e conhecer o relacionamento no contexto sociofamiliar de obesidade infantil do filho único.

\section{Método}

Para alcançar esses objetivos, optou-se pela pesquisa qualitativa que, segundo Lincoln e Guba (2005), é uma forma de compreender e de interpretar o mundo nos termos de seus atores sociais.

Participaram da amostra 8 (oito) famílias soteropolitanas com filhos(as) únicos(as) obesos(as) ${ }^{1}$ na faixa etária entre 7 e 10 anos, pertencentes a 4 (quatro) famílias de classe socioeducacional média alta e 4 (quatro) de classe socioeducacional baixa. (Quadro 1). As famílias foram selecionadas em consultórios e escolas por escolha intencional. A participação nas entrevistas foi voluntária, após conhecimento e assinatura do termo de consentimento informado e esclarecido.

Para definir o segmento socioeducacional das famílias, usaram-se os critérios estabelecidos pela Associação Brasileira de Empresas de Pesquisas (ABEP, 2008). As informações foram obtidas mediante a observação em domicílio e nas entrevistas semiestruturadas com as famílias.

Os critérios adotados para inclusão dos participantes foram:
- O estado nutricional das crianças. As crianças foram avaliadas mediante a aferição dos dados antropométricos (peso e estatura), que foram cuidadosamente aferidos segundo preconiza o Ministério da Saúde do Brasil (MS) (Barros e col., 2004). Em seguida, realizou-se a plotagem em gráfico dos dados aferidos, distribuindo-os em percentis e escores z (desviospadrão) do IMC segundo idade para sexo (5 a 19 anos): a avaliação nutricional para crianças com IMC entre P. 85-94\% é considerada como sobrepeso, aos valores acima do IMC P. 95\% obesidade. E obesidade grave como IMC P. 99\% para idade e sexo. Para os escores z considera-se obesidade os valores situados acima do +2 escore $z$ e obesidade grave valores acima do +3 escore z do IMC. Para tanto, como referência, utilizaramse os instrumentos segundo proposta da Organização mundial de saúde (OMS, 2007). (Quadro 1).

- Famílias formadas por casais cujos orçamentos e responsabilidades da casa eram compartilhados entre os cônjuges; de qualquer confissão religiosa; ser filho único biológico do casal.

Foram critérios de exclusão: famílias com criança filha única por óbito de outro filho; com filho único adotivo; com filho único portador de doenças crônicas; crianças com má formação ou enfermidades que interfeririam na coleta dos dados antropométricos; presença de alergias ou restrições alimentares; problemas crônicos que interfeririam na ingestão de alimentos pelas crianças.

\section{Instrumentos e procedimentos}

\section{Dados Antropométricos}

Os parâmetros antropométricos foram aferidos no domicílio da família, sendo explicada a razão para esse procedimento, mediante sua concordância. Para mensuração do peso foi utilizada balança de precisão modelo Clara 803 eletrônica portátil que possuía capacidade para 150 quilogramas e precisão de 100 gramas. A estatura foi mensurada por meio de antropômetro Seca, modelo 214 com base móvel. As orientações para as aferições antropométricas são preconizadas pelo Ministério da Saúde, publicadas em seu manual (Barros e col., 2004).

\footnotetext{
1 A fim de garantir a não identificação dos participantes, não apenas seus nomes foram alterados como quaisquer outras possíveis fontes
} de reconhecimento. 
Quadro I - Dados Antropométricos e avaliação do estado nutricional das crianças e seus pais, Salvador, 2008

\begin{tabular}{|c|c|c|c|c|c|}
\hline Nome fictício & Idade (anos e meses) & Peso $(k g)$ & Estatura $(\mathrm{cm})$ & IMC & Diagnóstico nutricional \\
\hline Nelson & $10 \mathrm{a} 3 \mathrm{~m}$ & 67,2 & 1,52 & 29,08 & Obesidade grave \\
\hline Sandra & 33 a $5 \mathrm{~m}$ & 53,6 & 1,59 & 21,20 & Eutrófico \\
\hline Ricardo & $33 \mathrm{a} 7 \mathrm{~m}$ & 72,0 & 1,72 & 24,33 & Eutrófico \\
\hline Danilo & $7 \mathrm{ag} \mathrm{m}$ & 34,0 & 1,26 & 21,41 & Obesidade grave \\
\hline Dandara & $47 a 6 \mathrm{~m}$ & 72,0 & 1,69 & 25,20 & Pré-obesidade \\
\hline Cássio & $53 \mathrm{a} 5 \mathrm{~m}$ & 78,0 & 1,68 & 27,63 & Pré-obesidade \\
\hline Emily & 8 a $10 \mathrm{~m}$ & 60,0 & 1,48 & 27,39 & Obesidade grave \\
\hline Sumaia & $49 a 11 \mathrm{~m}$ & 79,0 & 1,66 & 28,66 & Pré-obesidade \\
\hline Sérgio & $51 \mathrm{a} 2 \mathrm{~m}$ & 73,0 & 1,71 & 24,96 & Eutrófico \\
\hline Tatiane & 8 a $3 \mathrm{~m}$ & 59,3 & 1,39 & 30,69 & Obesidade grave \\
\hline Suzana & 48 a $3 \mathrm{~m}$ & 63,0 & 1,59 & 24,91 & Eutrófico \\
\hline Cássio & $56 \mathrm{a} 10 \mathrm{~m}$ & 79,3 & 1,63 & 24,84 & Eutrófico \\
\hline Lorenzo & $8 a$ & 51,6 & 1,30 & 30,53 & Obesidade grave \\
\hline Márcia & 38 a $5 \mathrm{~m}$ & 49,0 & 1,53 & 20,93 & Eutrófico \\
\hline Fausto & 44 a $8 \mathrm{~m}$ & 64,8 & 1,65 & 23,80 & Eutrófico \\
\hline Igor & $8 a 4 m$ & 52,6 & 1.46 & 24,67 & Obesidade grave \\
\hline Iara & 36 a $2 \mathrm{~m}$ & 69,0 & 1,68 & 24,44 & Eutrófico \\
\hline Ronaldo & $33 \mathrm{a} 6 \mathrm{~m}$ & 83,0 & 1,70 & 28,71 & Pré-obesidade \\
\hline Geórgia & $7 \mathrm{a}$ & 47,3 & 1,27 & 29,32 & obesidade grave \\
\hline Cristina & 34 a $5 \mathrm{~m}$ & 68,0 & 1,65 & 24,97 & Eutrófico \\
\hline George & $35 \mathrm{a} 7 \mathrm{~m}$ & 65,0 & 1,70 & 24,49 & Eutrófico \\
\hline Flávia & $7 \mathrm{a} 2 \mathrm{~m}$ & 41,3 & 1,23 & 27,29 & Obesidade grave \\
\hline Thaís & $34 \mathrm{a} 5 \mathrm{~m}$ & 54,3 & 1,52 & 23,19 & Eutrófico \\
\hline Paulo & 45 a $2 \mathrm{~m}$ & 70,0 & 1,69 & 24,50 & Eutrófico \\
\hline
\end{tabular}

\section{Scenotest}

O teste, elaborado por Gerdhild von Staabs em 1938, foi alterado e ampliado por Cerveny (1982). Foi utilizado como um instrumento auxiliar, em conjunto com os demais. Trata-se de um instrumento de investigação que visa, por meio de uma sessão familiar, avaliar a dinâmica e a relação existente entre os membros familiares e a criança. A sessão consiste em pedir à criança que disponha em uma caixa figuras que representam os membros familiares e objetos domésticos. 0 tempo médio despendido para a montagem variou em torno de 30 a 60 minutos, incluindo a montagem do teste e os comentários dos pais após a sua realização.

O material que compõe o Scenotest consiste em uma caixa com bonecos articulados de figuras humanas representando pai, mãe, avós e demais pessoas; utensílios domésticos, peças de madeira 
para construções diversas; personagens simbólicas; animais; alimentos por meio dos quais a criança poderá representar situações cotidianas vinculadas à dinâmica familiar.

As instruções para a aplicação do scenotest foram as seguintes: no ambiente domiciliar e na presença dos pais e da criança, a pesquisadora apresentou a caixa contendo o material do scenotest, convidando a criança a sentar no chão. Forneceu as instruções, abrindo a caixa do sceno: "Gostaria muito de conhecer como é a sua casa por dentro. Pode montar da maneira que quiser, usando o material dessa caixa como você desejar. Enquanto isso, eu irei fazer algumas anotações e gostaria que você me avisasse quando a cena estiver terminada. Esse é um espaço livre para você criar e peço a autorização para mais tarde fotografar a cena final com a finalidade de registrá-la, e gravar nosso encontro em áudio." (Figura 1).

Aos pais é feito um sinal de que não podem falar ou interferir durante a montagem. A entrevista foi gravada assim como foram tiradas fotografia da última montagem. A pesquisadora anota também o que ocorre durante a entrevista.

\section{Entrevista semiestruturada com os pais}

O roteiro (Anexo 1) de entrevista foi elaborado a partir da prática profissional da observação de famílias e com base na literatura consultada. As entrevistas com as famílias foram agendadas e realizadas em domicílio, gravadas e posteriormente, transcritas e analisadas. Consistiu em um relato inicialmente livre de como as famílias percebem a criança e a si próprias, seguido de questões complementares: dados sociodemográficos dos pais e da criança, avaliação da criança, relacionamento interpessoal, dinâmica familiar, dinâmica alimentar, lazer e itens associados à obesidade (Anexo 1).

\section{Resultados e Discussão}

A análise dos dados avaliou a relação entre os elementos obtidos nas entrevistas, no Scenotest e em observações etnográficas, identificando elementos comuns e diferenciais entre as histórias das crianças e seus contextos sociofamiliares. Posteriormente, os resultados foram agrupados e condensados em três núcleos norteadores da análise: filho único, dinâmi- ca familiar e obesidade infantil, que serão apresentados a seguir conjuntamente à sua discussão.

\section{Filho único}

A categoria analítica "filho único" apresentou-se como a de nível mais geral, estando aqui representada como: filho totalmente inesperado; gravidez não planejada e instabilidade conjugal.

\section{Filho totalmente inesperado: grupo socioeduca- cional alto}

A Emily, ela veio quando eu nem esperava mais, né? apesar de desejar muito, não tinha mais esperança que ela viesse. Depois de algumas cirurgias tratamentos e tudo... Já tinha desistido, ai apareceu a Emily (Sumaia, mãe de Emily).

Dos oito casos estudados, três resultaram de concepção tardia a partir de 40 anos, todas as mães do grupo socioeducacional alto que não esperavam mais ter filhos por estarem desenganadas dessa possibilidade. Essa foi uma dinâmica que marcou o filho único no que tange à sua estrutura vincular: não ser esperado; figuras parentais que tinham um estilo de vida já definido e cuja adaptação a um neonato podia ser difícil; mães e pais que podem não ter tido uma "maturação" para uma abertura às mudanças que a gestação e o nascimento ocasionariam em suas vidas. De fato, o período pré-natal e as experiências primárias da criança, assim como o posterior desenvolvimento, têm sido apontados como fatores responsáveis por doenças crônicas como obesidade, entre outras (Kuh e Ben-Shlomo, 2004).

Esses pais declararam optar por um filho único devido à saúde materna e à faixa etária, visto que a gravidez ocorreu de maneira tardia. Assim, foi o filho em si que emergiu como exceção e não o fato de ser único.

\section{Gravidez não planejada: grupo socioeducacional baixo}

A gravidez não foi planejada, mas ele foi desejado (Cláudia, mãe de Nelson).

Cinco nascimentos resultaram de gravidez não planejada, quatro deles pertencentes ao grupo socioeducacional baixo. Nóbrega e Campos (1996) relatam que a presença da ambiguidade de sentimentos quanto à maternidade no estabelecimento 
do vínculo mãe-filho tem a possibilidade de estabelecer conflitos que se podem situar como gênese da obesidade infantil.

As quatro famílias, ao optarem pelo filho único, apresentaram justificativas em termos de exigências de ordem econômica:

No momento não, porque ele (o pai) tá sem trabalhar, tá pequena... eu não tenho a minha casa... aqui é a casa de minha mãe... Num dá certo com o problema que ela tem... dois filhos, tá muito difícil... eu vejo a dificuldade que eu passo com uma... pra passar com duas, num dá não. No momento minha cabeça num quernem um (Cristina, mãe de Georgia).

A urbanização, a globalização, a situação econômica, a situação de saúde dos pais e a sociedade de consumo afetam diretamente a taxa reprodutiva populacional. Como supracitado, o número de mulheres com apenas um filho aumentou (IBGE, 2007). As famílias soteropolitanas entrevistadas apontaram a ocorrência do mesmo fenômeno, embora de modo ainda emergencial.

\section{Filho único e instabilidade conjugal}

Em dois casos, as mães justificaram o impedimento para ter outro filho com questões relativas à guarda em situação de um possível divórcio. Na justificativa por um filho unigênito, além de incluir o tema divórcio, uma mãe descreveu os elementos que a levaram ao filho unigênito: instabilidade econômica e relacional; conflitos entre o casal e guarda do filho; insegurança quanto ao futuro e projetos de vida; dificuldades econômicas ligadas à saúde, educação, alimentação e ao lazer:

Mas assim, a gente já tá num mundo, que eu acho que um filho na vida de um casal é suficiente e segundo, tá dando certo até hoje, estamos juntos, mas amanhã ninguém sabe... Um só você carrega, e dois? Outra coisa também, o futuro da gente, a gente não tá conseguindo dar futuro pra um, quanto mais pra dois... Porque eu vou dizer que hoje a gente tá junto, mas amanhã a gente não sabe. Aívai discutir com que vai ficar com quem deixa de ficar. E com 3? Educação? Porque neguinho acha que educação é só dar comida, comida, comida. Pra mim educação não é só comida. Edu- cação pra mim é... Uma boa alimentação, um bom colégio, um bom lazer, um bom remédio pra dentro de casa, pra saúde (Márcia, mãe de Lorenzo).

Essa mãe apontou a cultura do consumo como já constituindo a subjetividade da criança e retratou como a sua condição subjetiva foi "informada" e transformada pelo processo que Berenstein (2007) denomina transubjetividade: “Tudo é dele. Até uma coisa que a gente for comprando pra mim, ele acha que é dele." (Cláudia, mãe de Igor).

Portanto, a categoria filho único pode ser interpretada como a tradução subjetiva de uma opção contemporânea estruturada em termos macrossociais, históricos, sociais e econômicos. Em nosso estudo, ocorreu uma diferenciação para essa opção associada ao grupo socioeducacional: na classe alta, motivos alegados de saúde e idade; no grupo socioeducacional baixo, principalmente fatores econômicos. Finalmente, comum a todos os casais, a insegurança quanto ao futuro parece estar atuando fortemente no presente, direcionando projetos de vida.

\section{Dinâmicas familiares}

Na categoria dinâmica familiar, o enfoque será nos elementos intersubjetivos envolvendo os pais e a criança.

\section{Pai: Presença e ausência}

Através de atitudes, a maioria dos pais pareceu influenciar não apenas na origem, mas na manutenção da obesidade infantil (Spada, 2005). Em seis casos, o pai e a mãe da criança residiam no mesmo domicílio, sendo que a figura paterna não estava necessariamente vinculada à sua presença física no domicílio. Dos oito casos estudados, quatro pais manifestaram desinteresse pela criança, podendo ocorrer também o inverso (o pai não habitando com a criança, mas presente):

"Lorenzo apresentou várias doenças: 'desmaio, refluxo, febre' (sic) e de dois meses de idade em diante, foi que ele começou a engordar. [...] Mas o problema dele, como a psicóloga já disse, era pela falta do pai. [...]." (Márcia, mãe de Lorenzo).

Um pai ausente é diferente de um "pai que não está,", pois se o primeiro marca a subjetividade e obriga a simbolizá-lo dada a sua não presença, o segundo marca um tipo de vínculo, pois o lugar do que 
não está é o de uma ausência fortemente impregnada de uma presença esperada. (Berenstein, 2001).

Assim, na família de Danilo, o pai, ao exercer o papel de "amigo" do filho em situações familiares como a de "abastecer a despensa de alimentos calóricos," (segundo revela a mãe), estabeleceu-se como um "pai que não está”. Nessa dinâmica, emergiu a situação da obesidade infantil, em que o pai pareceu se sentir culpado e ausente fisicamente da família: por trabalhar fora o dia todo e por cada vez mais optar por conquistas maiores no mercado de trabalho, situando assim o fenômeno do declínio do diálogo e do convívio na família (Lamounier e Parizzi, 2007). Desse modo, o pai tentou se aproximar do filho por meio de um diálogo representado pela permissividade alimentar.

Esses dados apontam a importância da figura paterna na gênese e manutenção da obesidade, principalmente porque a sua presença pode reorganizar o ambiente familiar, favorecendo o manejo da obesidade infantil.

\section{Mãe: Dinâmica do aleitamento materno e apego materno}

"Mama até hoje com oito (8) anos, se deixar." (Cássio, pai de Tatiana).

Todas as crianças do estudo foram amamentadas ao seio de forma não exclusiva por mais de 6 meses, exceto uma cuja dieta consistiu em leite artificial. Quatro crianças foram aleitadas após os dois anos de idade. Rabinovich e Carvalho (2001) observaram que o desmame tardio está associado a um desajuste no casal. Na relação mãe/bebê, não teria havido a "interdição", uma atribuição da denominada "função paterna": instituir o simbólico por meio da separação da "natureza", ou seja, da união mãe/bebê. Sem a "interdição", mãe e criança não se diferenciam entre si. Essa "ausência de um si próprio" estaria apresentada na forma da ocupação de espaço do obeso e da ingestão alimentar como modo de lidar com o vazio da angústia por não haver um "si próprio" (Berenstein, 2001).

Baseada em nossa casuística, apontam-se duas dinâmicas imbricadas no contexto mãe/ filho:

- Mãe intrusiva: mãe que não respeita os tempos e os desejos da criança, portanto não é sensível às necessidades ligadas ao desenvolvimento. Seria o caso em que o uso do poder se sobrepõe ao do amor, seja por ansiedade materna, superproteção ou autoimagem narcísica projetada na criança. A “invasão" de mães foi observada durante a aplicação do Scenotest, dando ordens ao filho, considerações, corrigindo-o. Esses comportamentos, associados a um desmame tardio, reforçam a interpretação de que a mãe invade o mundo interno do filho ocupando esse espaço, e a criança passa a ocupar o espaço externo pela obesidade. Esse quadro se associa também a um aumento de dependência que parece ser alimentada pela mãe e pela própria criança.

- Mãe fusionada: aquela que não se separou da criança. Uma mãe está fusionada com o seu filho quando ele é uma extensão narcísica de si própria, não tendo existência por ela mesma para a mãe. Tassara (2006), em seu estudo em famílias com obesidade infantil, situa a existência da fusão entre mãe e filhos associada ao distanciamento do pai.

\section{Dinâmica do casal}

\section{0 trabalho dos pais}

Os casais passaram por diversas instabilidades, uma delas ligada ao tipo de ocupação. Nas famílias dos oito casos estudados, dois estavam desempregados, um aposentado, um reiniciava uma carreira profissional, um optou por trabalhar em casa pelo filho e três encontravam-se empregados.

O caso mais paradigmático foi relatado por uma arquiteta cujo marido foi constantemente transferido de cidade devido ao trabalho, isolando ela e o filho em uma redoma, com consequências para a sociabilidade de ambos. Com a separação, a mãe retornou ao trabalho, o filho apresentou distúrbio alimentar e escolar, mas, com o reequilíbrio materno, o menino pareceu também estar se estabilizando.

Portanto, o modo de subsistência, a realidade socioeconômica e a redução do convívio social ao contexto familiar refletem-se diretamente na dinâmica do casal e devem ser apontadas como um elemento a ser considerado na dinâmica da obesidade infantil, embora presentes também em inúmeras outras problemáticas.

\section{Sociabilidade do filho único}

"Ela sempre teve uma dificuldade de... de... assim... entrosar de agrupar. Por ser filha única eu acho" (Sérgio pai de Emily). 
Na dinâmica familiar encontrada na família de Nelson, pode-se perceber:

"Dificuldade de relacionamento. Faltou muito estimular a brincadeira de rua, o convívio dele com outras crianças [...] Então foi sempre eu, ele e o pai. ... Mas nada muito de estar com amizade. Eu acho que a gente com isso, se fechou muito, só nos três" (Sílvia, mãe de Nelson).

Essa dinâmica pode ser entendida face aos conceitos de espaços intra, inter, transubjetivos. A família contemporânea vive uma vida de "hiperindividualização”. Esse processo enfraquece os vínculos humanos que são estabelecidos, alimentados e vivenciados no espaço do diálogo que vem se estabelecendo no meio familiar de modo fragmentado.

Nos nossos casos, a criança obesa recebe apelidos, o que a marca de modo pejorativo:

"Baleinha fora d'água... (por isso) Ela ficou sem comer, mas depois eu a convenci." (Thaís, mãe de Flávia).

A interação interpessoal sempre é intermediada pela imagem refletida, que tanto alimenta a autopercepção quanto a valoração de cada um dos parceiros. $\mathrm{O}$ apelido ajuda a estigmatizar a criança obesa, influenciando no seu modo de se relacionar com o outro.

\section{Obesidade infantil}

\section{Dinâmica alimentar}

O estilo urbano contemporâneo marcado pelo sedentarismo, impacto dos meios de comunicação e modos de consumo, configurado pelo poder econômico e socioeducacional, podem ser tipificados pela dinâmica familiar alimentar da família de Danilo. A mãe descreveu o papel que exercia nessa família, especificando suas atitudes e desejos em alimentar o filho de forma a atender não apenas aos seus desejos, mas também deixar transparecer, para si mesma e para os outros, o fato de assim exercer o seu papel de "boa mãe", ao oferecer qualidade na alimentação do filho e da família: "A alimentação aqui em casa, só entra alimentação natural [...]" (Dandara, mãe de Danilo).

No entanto, a mesma descreveu assim o dia de extrapolar: "Final de semana é liberado pra Danilo: chocolate, batata frita, é... acarajé e refrigerante.”
Sobre o pai, a mãe relatou: "O pai... compra batata frita na rua, e enche o armário de merenda...”.

Ilustrando os meios de comunicação e o consumo:

Danilo gosta de receber a mesada e ir pro shopping [...] não sabe lidar bem com o dinheiro. $O$ negócio dele é comprar [...] Pede o brinquedo (da promoção da ' $X$ '). Porque na verdade, o que ele come da ' $X$ ' é o suco de laranja e a batatinha. Porque o resto fica tudo. Ele só quer o brinde... (Dandara, mãe de Danilo).

Considerando a lógica do consumo alimentar, destaca-se a centralização que a comida ocupa na família e na sociedade contemporânea brasileira. A "globalização" é, para Berenstein (2007), uma realidade em que a supressão dos limites internacionais proporciona modificações de "valores, significações e ideais" na família conduzindo-a a um "status de consumidor" - em que, numa situação social anterior, as pessoas se situavam como "cidadãos".

\section{Atividade física}

Vários pesquisadores, como Tremblay e Willms (2003), mostram que a deficiência na atividade física das crianças está diretamente relacionada ao aumento da obesidade bem como o tempo dedicado pela criança a assistir a televisão ou a jogos eletrônicos.

Agora ela émuito parada, num gosta de caminhar, num gosta de atividade física... Num tem outras crianças pra brincar...num tem outro jeito, ela vai engordar mesmo. Num é que ela come, é que ela num gasta nada... (Sumaia, mãe de Emily).

A possibilidade de acesso da população de nível socioeducacional baixo à atividade física, seja por questões econômicas, seja por questões de estrutura de lazer e segurança do bairro onde residem, pode ser escassa.

Quando eu fui no cardiologista, ele falou que tem que botar ele pra praticar um esporte. $\varepsilon$ isso já é gasto, pra uma pessoa pra levar, e tudo, $e$ o salário que a gente ganha, num dá pra fazer isso. Ainda tem que pagar transporte (Cláudia, mãe de Igor).

Além das situações citadas, foram apontadas pelas famílias situações relacionadas ao estigma so- 
cial e à não aceitação social da obesidade infantil:

[...] Ele reclama. Tava botando ele pra caminhar de manhã, mas o problema dele é que as pessoas passam e: Ah!! Gordinho, tem que caminharmesmo... tá gordinho, tem que perder peso. $\varepsilon$ aí ele começou a dizer: gente idiota!!!...num sei o quê... e aífica com aquele trauma que tá gordinho, tem que caminhar, e fica com respostas agressivas (Cláudia, mãe de Igor).

Assim, ocorreu tanto a discriminação social da obesidade infantil em si quanto a reação da criança a ela. A criança, não apenas desistiu de caminhar nas ruas por desejar evitar o sofrimento das agressões verbais, como também incorporou os olhares negativos dos outros.

A maioria das crianças do nosso estudo não aderiu à atividade física de forma regular; e as causas dos impedimentos variaram entre a censura do olhar do outro, as precárias condições socioeducacionais ou estruturais de lazer, a não aceitação pela própria criança de seu corpo, impedindo-a não apenas de obter os benefícios biológicos da atividade física em si, mas, principalmente, da oportunidade de propiciar outras situações vinculares.

\section{Percepção da obesidade infantil na família}

Dos oito casos estudados, apenas duas famílias reconheceram a obesidade no filho. Na entrevista domiciliar, a maioria dos pais designou a obesidade da criança como algo sem importância, minimizando, desconhecendo, negando ou terceirizando a obesidade de seus próprios filhos, como apenas culpada pelos médicos e/ou nutricionistas. Muitas vezes, toda a família da criança estava envolvida nesse processo de negação.

Em três dessas famílias, os pais acreditavam que a obesidade infantil terá resolução espontânea:

"Vai caminhando para a normalidade" (Sílvia mãe de Nelson).

"Danilo não é gordo. Ele está inchado [...]" (Dandara, mãe de Danilo).

"Acredito que com a chegada da adolescência, o peso dela vai equilibrar" (Sérgio, pai de Emily).

A obesidade apresenta graves repercussões orgânicas e psicológicas, sendo difícil o seu tratamento. Principalmente quando negada pela criança ou pela família, ou configurado em expectativas mágicas, as chances para a criança e o adolescente permanecerem obesos e as suas complicações para a saúde são mais elevadas ainda (Fisberg, 2005).

As crianças revelaram sua autopercepção acerca de sua obesidade atual, no modo como se sentem discriminadas diante das distinções e preconceitos sociais por meio dos principais sentimentos expostos: dor, tristeza e desamparo.

"Quero ser light quando crescer" (Georgia, 7 anos).

\section{Sintese}

Dentre as situações familiares encontradas nesse estudo, duas merecem destaque. A primeira: há várias dinâmicas familiares diferentes associadas à obesidade infantil; a segunda, uma mesma ordem de dinâmicas sociais conduz tanto ao filho único quanto à obesidade infantil exógena.

A dinâmica familiar principal, observada em todos os casos, refere-se à invasão do espaço transubjetivo na intersubjetividade, qual seja, nos vínculos, o que ocorre de modo singular em cada caso. Vive-se em uma época em que a cultura situa a alimentação em um lugar central. Esse status a ela atribuído tem produzido uma imposição de sua presença que influencia a dinâmica familiar dentro da lógica da hipermodernidade. A criança, por necessitar "estar" com o outro para constituir o vínculo, na ausência de outras opções, une-se ao alimento em uma realidade intersubjetiva. 0 impacto do espaço transubjetivo pode ser notado em vários aspectos relatados pelas famílias:

Trabalho: $\mathrm{O}$ atravessamento da lógica da hipermodernidade se impõe aos pais, assediados por maiores conquistas no mercado de trabalho ou inertes na lógica do consumo, assim como vivenciando o desemprego. Isso se reflete tanto na dinâmica do casal como em uma redução do convívio social. Associada à perda de vínculos de pertencimento e reconhecimento, as relações entre os membros familiares sofrem perturbações, havendo perda da subjetividade por não estabelecimento de vínculos tanto na vida laboral quanto na social. Dessa forma, o poder do espaço público, incidindo no modo de subsistência impacta, decide e comanda o pensar, 
valores e crenças na intersubjetividade familiar, interferindo em todos os níveis socioeducacionais.

Presença e ausência: Tanto a figura parental pode estar fisicamente ausente quanto não se "apresentar" como tal. Um "pai/mãe que não está" é diferente de um "pai/mãe ausente". Em alguns casos dessa presença/ausência, os pais direcionam o melhor da sua energia a outros campos, como ao trabalho, por exemplo, e decrescem em disposição para o diálogo com os filhos, configurando o fenômeno do declínio do convívio nas relações contemporâneas na família. Esse declínio aparece na dificuldade de colocar limites, incidindo no modo de alimentação. Em três casos estudados, a mudança do posicionamento paterno reorganizou o ambiente familiar, favorecendo o manejo da obesidade infantil. A relação intersubjetiva define e impacta o outro com a sua presença, sendo esse o lugar constituinte do vínculo cujos efeitos positivos da alteridade podem restaurar a qualidade vincular familiar.

Falta de lugar da criança na família e dessa no mundo: O "estar" é o lugar constituinte do vínculo. A família que não encontra lugar, não se vincula: falta de moradia e de recursos materiais, doença e falta de acesso ao serviço público de saúde, violência urbana, podem se atrelar a uma ausência de lugar na vida da família para a criança ou para irmãos, dominados pela lógica. Na ausência do estar, não ocorre o vínculo e a criança fica resumida ao próprio corpo, quando a obesidade aparece como sintoma da falta de lugar da família, expressa na ocupação de espaço externo pelo corpo da criança.

Instabilidade familiar: Divórcios e separações estão no horizonte dos casais que se sentem inseguros quanto ao futuro, quer na relação quer no seu posicionamento no mundo. Nessa medida, o filho único aparece como uma opção que apenas retrata esse sentimento de instabilidade. Os pais não se sentem encorajados a ter mais filhos por temerem não dar conta dos cuidados necessários, associados, ou não, a uma separação conjugal. Dentro do quadro de instabilidade nos vínculos familiares, o irmão pode ser muitas vezes o elemento mais estável familiar, atuando como suporte afetivo e companheiro nas atividades lúdicas. A ausência de um irmão, portanto, projeta, com maior intensidade, dificuldades na dinâmica social. Assim, a criança filha única fica isolada no mundo domiciliar e reduzida a um universo restrito ao número três. Insegurança quanto ao trabalho, à moradia, à violência urbana, dificuldades econômicas, todos esses elementos se organizam configurando o que se denomina instabilidade familiar.

os fazeres: Em meio ao status atribuído à alimentação na sociedade "obesogênica", a dinâmica alimentar familiar adquire vida própria e identidade em cada um dos espaços psíquicos. A criança obesa é discriminada inicialmente pelo olhar da mãe, em seguida pelos parentes e sociedade, todos construtores do estigma social associado à obesidade na sociedade atual. Esse estigma gera e sustenta a discriminação na qual a própria criança constrói sua autoimagem negativa. Associada às situações referentes à discriminação social da obesidade por meio da censura do olhar do outro e em meio a estruturas de lazer, acessíveis ou não, a maioria das crianças não aderiu à atividade física de forma regular, impedindo-a não apenas de obter os benefícios da atividade física, mas principalmente, da oportunidade de proporcionar situações vinculares outras. Assim, elementos da transubjetividade levam à perda da subjetividade por destruições - ou não estabelecimento - de vínculos, refletidos tanto na dinâmica alimentar como na atividade física.

Sociabilidade: Desde o início da vida, a criança, por meio da sua tripla inscrição simultânea, necessita do intercâmbio com o outro como realidade externa a fim de se constituir como sujeito e instituir-se no processo identificatório. A "hiperindividualização" familiar engessa os fazeres entre as pessoas e o mundo, fazeres que são o nascedouro de presenças de vínculos e da subjetividade. 0 vínculo demanda uma relação de pertença e, portanto, estabelece-se na presença do outro. No que se refere à sociabilidade do filho único, foram identificados os seguintes aspectos: autoimagem negativa da criança, refletida pelos apelidos, dificultando relacionar-se com o outro; dinâmica instituída na família de restringir-se à vida privada. Esses são elementos que constituem e apontam uma deficiente sociabilidade infantil decorrente do modo de vida dos pais.

Relação mãe/criança: Destacam-se duas dinâmicas em nível intersubjetivo, envolvendo especialmente a relação mãe/criança: fusão e intrusão. Associada 
à fragilidade paterna, emergiu a dinâmica da fusão mãe/criança, em que não havia diferenciação entre a mãe e a criança. Há casos em que a mãe atua de modo intrusivo, e com excesso de poder, desvirtuando a relação a ponto de a criança vir a se tornar um objeto a seu serviço. A mãe a mantém como um bebê, não permitindo sua separação e crescimento.

Diferenças associadas ao nível socioeducacional e gênero: O motivo alegado para o filho ser único esteve associado ao grupo socioeducacional: motivos de saúde no grupo alto e condições socioeconômicas no grupo de baixo nível. Não se observou diferenças ligadas a gênero. Do ponto de vista da intervenção, evidentes diferenças se configuram na possibilidade de acesso e uso de possíveis recursos terapêuticos, quer em nível individual quer em nível grupal. Outra diferença que emergiu foi o maior envolvimento dos pais com crianças de nível socioeducacional baixo.

\section{Conclusão}

As dinâmicas familiares indicaram contextos abrangentes de natureza social, cultural e histórica da sociedade, que parecem favorecer ambas as condições, a da obesidade infantil e a condição de filho único. A situação familiar contemporânea, com ênfase no individualismo, favorece que elementos transubjetivos - o modo de pensar hipermoderno, dificuldades econômicas e insegurança quanto ao futuro - tornem-se prevalentes em nível intersubjetivo, gerando uma motivação para o filho único, que propicia um estreitamento das possibilidades intrasubjetivas, ou seja, vinculares. Por isso, o filho único pode vir a encontrar, logo ao nascer, condições propiciadoras a que sua vinculação básica com a figura materna não se processe de modo pleno, ocasionando que parte do que não recebe seja derivada para uma satisfação no alimento. Se nem todo filho único é obeso e nem todo obeso é filho único, essa condição pode ser facilitadora da outra, na medida em que a situação sociocultural-histórica da sociedade hipermoderna pareça direcionar ambas as condições. A cultura do consumo interfere no tipo de alimentação oferecida, no modo de alimentação, de ludicidade e de sociabilidade infantil, assim como o estreitamento das possibilidades vinculares, intrapessoais, inter-pessoais, transpessoais, acresce-se ao fato de não ter irmãos.
Tendo em vista a obesidade exógena da criança unigênita contemporânea na família, cabe à equipe multiprofissional de saúde esquecer o seu "discurso" e assumir a atitude de escuta da família, recebendo delas seus modos de construir a situação familiar na sua dimensão sociocultural e histórica. A equipe aprende com os pais respondendo às perguntas à medida que elas vão surgindo e recebendo deles o melhor modo de fazer. Isso traz a possibilidade de humanizar e compreender a família nos parâmetros da educação em saúde, enfatizando a importância da presença dos pais, do contato físico e diálogo com a criança, enfatizando ser a faixa etária da infância a de melhor prognóstico contra a obesidade.

\section{Anexo I: Entrevista Semiestruturada \\ Caracterização da Criança}

Nome:

Data

Peso do nascimento: ___ $\mathrm{kg}$

Criança: Peso atual:___ kg Estatura atual:___cm

Pai: $\quad$ Peso atual:___ kg Estatura atual:___cm

Mãe: Peso atual:___ kg Estatura atual:___cm

\section{Caracterização dos Pais}

\section{Nome}

Pai:

Mãe:

\section{Data de nascimento}

Pai:

Mãe:

\section{Estado civil}

Pai:

Mãe:

\section{Naturalidade e nacionalidade}

Pai:

Mãe:

\section{Religião}

Pai:

Mãe:

\section{Escolaridade}

Pai:

Mãe: 


\section{Profissão}

Pai:

Mãe:

\section{Atuação profissional}

Pai:

Mãe:

\section{Breve História da Família}

- O casamento e a gravidez foram planejados?

- Tem planos de ter outro filho(a) algum dia? Se não, por que ter um filho(a) único?

- Como foi o nascimento do seu filho(a)?

- Atualmente a criança encontra-se em tratamento de alguma doença? Se sim, especifique.

- Já foi internado alguma vez?

- Hereditariedade familiar ou alguma doença atual na criança (Hipertensão arterial, Diabetes, doenças cardiovasculares, problemas ortopédicos, obesidade, em relação ao sono ou doenças mentais)?

\section{Personalidade da Criança}

- O que vocês pensam sobre seu filho(a)?

- A criança apresenta medo de alguma coisa?

- O seu filho(a) já apresentou comportamentos como roer unhas, bater a cabeça ou balançar-se continuamente?

- Já observaram se seu filho(a) algumas vezes se sente inseguro(a) ou retraído(a)?

\section{Relacionamento Interpessoal}

- Com que idade a criança ingressou na escola?

- Como a criança se adaptou e interagiu com a escola?

- Como é o relacionamento da criança com colegas e professores e familiares?

- De uma forma geral, como é o relacionamento da criança com as pessoas?

- Como os pais acreditam que ela vê nos seus relacionamentos?

- A criança faz amizades com facilidade ou não?

- A criança já fez algum comentário em relação ao seu peso?

- A criança acha que o seu peso interfere de alguma forma no relacionamento com as pessoas? Se sim, de que forma?

\section{Dinâmica Familiar}

- A mãe trabalha fora? Por quanto tempo? E o pai?
- Quem cuida da criança quando os pais estão ausentes?

- Há outras pessoas que compõem a família?

- A família já morou em outros lugares ou não?

- Como cada um dos pais se relaciona com o filho(a)?

- O que a família gosta de fazer junto?

- Qual o lazer da família?

- A família sai junto? Para onde?

- Qual é, para você, o sentido da presença de seu (sua) filho(a) na sua vida?

\section{Dinâmica Alimentar Familiar}

-A criança recebeu leite materno? Por quanto tempo?

- Como ocorreu o desmame?

- Você acha o seu filho(a) obeso, gordo, normal ou magro?

- Como você vê a obesidade de seu (sua) filho(a)? Isso preocupa você?

- Você exerce esse cuidado da alimentação na relação com seu (sua) filho(a)? Como é para você?

- Ele pede para repetir? Quem dá mais?

- Vocês comem assistindo a TV?

- Aos finais de semana vocês comem fora de casa?

- Associam lazer com alimentação?

- O que você acha quando a família almoça juntos?

- A criança pede comida? Que tipo de comida?

- Trocaram um bom comportamento por algum alimento? Chantageia?

- A criança fica sozinha, mesmo com alguém em casa?

- Você cede às vontades da criança? Ou diz não logo de cara? (Paterno x Materno)

- Que tipo de alimentação você compra para a família?

- E para a criança o quer você gosta de comprar? Ele pede o que comprar?

- Você leva compras para ele? O que ele pede?

- Você percebe que a TV influencia no comportamento ou a alimentação do seu filho? Como?

\section{Lazer Familiar}

- O que a família faz para se divertir? Em casa? E fora de casa?

- Pra onde costumam sair?

- Praticam atividade física regular?

- Onde a criança brinca? Quanto tempo? Casa ou Playground? 
- Ele(a) brinca sozinho? Ou pede para brincar com outras crianças?

- Qual brincadeira/atividade você prefere?

- Ele(a) gosta de caminhar?

- Como brinca? Eletrônicos?

\section{Obesidade}

- História.

- Ele(a) tem algum apelido?

- A criança já recebeu algum apelido por ser gordinha?

- Como ela reagiu aos apelidos?

- Gostaria de comentar algo que eu não lhe tenha perguntado e que julgue importante dizer?

\section{Referências}

ABEP - ASSOCIAÇÃO BRASILEIRA DE EMPRESAS DE PESQUISA. 20o8: critérios de classificação econômica do Brasil. São Paulo, 2008. Disponível em: <www.abep.org/novo/Utils/FileGenerate. ashx?id=46>. Acesso em: 8 abr. 2009.

BARROS, D. C. de et al. Vigilância alimentare nutricional - Sisvan antropometria: como pesar e medir. Brasília, DF: Ministério da Saúde, 2004. (Série A. Normas e Manuais Técnicos). Disponível em: <http://lproweb.procempa.com.br/ pmpa/prefpoa/sms/usu_doc/album_seriado_de antropometria.pdf $>$. Acesso em: 8 abr. 2009.

BERENSTEIN, I. El sujeto y el otro: de la ausencia a la presencia. Buenos Aires: Paidós, 2001.

BERENSTEIN, I. Del ser al hacer: curso sobre vincularidad. Buenos Aires: Paidós, 2007.

BERNARDI, F.; CICHELERO, C.; VITOLO, M. R. Comportamento de restrição alimentar e obesidade. Revista de Nutrição, Campinas, v. 18, n. 1, p. 85-93, 2005 .

CERVENY, C. M. O. O Scenotest como instrumento de investigação das relações familiares, no processo do diagnóstico psicológico com crianças e adolescentes. 1982. Dissertação (Mestrado em Psicologia)-Pontifícia Universidade Católica de São Paulo, São Paulo, 1982.
FISBERG, M. (Org.). Atualização em obesidade na infância e adolescência. São Paulo: Atheneu, 2005.

HERSCOVICI, C. R. A escravidão das dietas: um guia para reconhecer enfrentar os transtornos alimentares. Porto Alegre: Artes Médicas, 1997.

IBGE - INSTITUTO BRASILEIRO DE GEOGRAFIA E ESTATÍSTICA. Pesquisa Nacional por Amostra de Domicílio, 2007: síntese dos indicadores sociais uma análise das condições de vida da população brasileira. Rio de Janeiro, 2008. Disponível em: <http://biblioteca.ibge.gov.br/visualizacao/ monografias/GEBIS\%20-\%20RJ/sintese_indic/ indic_sociais20o8.pdf >. Acesso em: 10 set. 2009.

INTERNATIONAL OBESITY TASK FORCE. The global epidemic. Copenhagen, 2002. Disponível em: <http://www.iaso.org/iotf/obesity/ obesitytheglobalepidemic/>. Acesso em: 5 jul. 2009.

KEHL, M. R. Em defesa da família tentacular. In: GROENINGA, G. C.; PEREIRA, R. C. (Coord.). Direito de família e psicanálise. Rio de Janeiro: Imago, 2003. p. 205-206.

KUH, D.; BEN-SHLOMO, Y. A life course approach to chronic disease epidemiology. 2. ed. Oxford: Oxford University Press, 2004.

LAMOUNIER, J. A.; PARIZZI, M. R. Obesidade e saúde pública. Cadernos de Saúde Pública, Rio de Janeiro, v. 23, n. 6, p. 1497-1499, 2007.

LEÃO, L. S. C. de S. et al. Prevalência de obesidade em escolares de Salvador, Bahia. Arquivos Brasileiros de Endocrinologia e Metabologia, São Paulo, v. 47, n. 2, p.151-157, 2003.

LINCOLN, Y. S.; GUBA, E. G. Paradigmatic: controversies, contradictions and emerging confluences. In: DENZIN, N. K.; LINCOLN, Y. S. Handbook of qualitative research. London: Sage Publications, 2000. p. 163-188.

MAGALHÃES, A. S.; FÉRES-CARNEIRO,

T. Transmissão psíquico-geracional na contemporaneidade. Psicologia em Revista, Belo Horizonte, v. 10, n. 16, p. 243-255, 2004.

NÓBREGA, F. J.; CAMPOS, A. L. R. Distúrbios nutricionais e fraco vínculo mãe/filho. Rio de Janeiro: Revinter, 1996. 
WHO - WORLD HEALTH ORGANIZATION. Growth reference data for 5-19 years. Geneva, 2006. Disponível em: <http://www.who.int/growthref/ en/>. Acesso em: 4 jul. 2008.

PETRINI, G. Políticas sociais dirigidas à família. In: BORGES, A.; CASTRO, M. (Org.). Família, gênero e gerações: desafios para as políticas sociais. São Paulo: Paulinas, 2007. p. 207-231.

PUGET, J. Intersubjetividad: crisis de la representación. Psicoanálisis, Buenos Aires, v. 25, n. 1, p. 1-17, 2003. Disponível em: <http://www. apdeba.org/publicaciones/2003/o1/pdf/Puget. pdf $>$. Acesso em: 4 jul. 2008.

RABINOVICH, E. P.; CARVALHO, A. M. A. Modo de morar e modo de cuidar: uma proposta de tipologia. Psicologia, Ciência e Profissão, Brasília, DF, v. 21, n. 2, p. 74-85, 2001.

SINGLY, F. Família e individuação. Rio de Janeiro: FGV, 2000.
SOCIEDADE BRASILEIRA DE PEDIATRIA.

Obesidade na infância e adolescência: manual de orientação. São Paulo, 2008.

SPADA, P. V. Obesidade infantil: aspectos emocionais e vínculo mãe/filho. Rio de Janeiro: Revinter, 2005.

TASSARA, V. Obesidade na infância no contexto sócio familiar: possibilidades de (des) construção e (res) significação de identidades (pré) escritas. 2006. Dissertação (Mestrado em Psicologia)Universidade Federal de Minas Gerais, Belo Horizonte, 2006.

TREMBLAY, M. S.; WILLMS, J. D. Is the Canadian childhood obesity epidemic related to physical inactivity? International Journal of Obesity and Related Metabolic Disorders, London, v. 27, n. 9, p. 1100-1105, 2003. 